\title{
Image-Guided Adaptive Radiation Therapy
}

National Cancer Institute

\section{Source}

National Cancer Institute. Image-Guided Adaptive Radiation Therapy. NCI Thesaurus.

Code C116432.

A type of radiation therapy that uses information gathered during the treatment cycle to inform, guide, and alter future radiation treatments with respect to location and dose. 